\title{
Monozygotic twins discordant for Goldenhar syndrome
}

\author{
Leonardo Lima Verona, ${ }^{1}$ Nicholas Godoy Canazza Damian, ${ }^{1}$ \\ Lucimara P. Pavarina, ${ }^{2}$ Cristina H. F. Ferreira, ${ }^{2}$ Débora Gusmão Melo ${ }^{3}$
}

\begin{abstract}
Objective: To report on a pair of monozygotic female twins discordant for Goldenhar syndrome.

Description: The affected twin was a girl, who was delivered by caesarean section at 35 weeks' gestation. Her birth weight was $2,170 \mathrm{~g}$, length $42.5 \mathrm{~cm}$, head circumference $30 \mathrm{~cm}$ and her APGAR scores were $3 / 7$. After birth the child developed severe respiratory distress and had to be moved to the neonatal intensive care unit (ICU). The other twin was a girl, born weighing 3,200 g with a length of $49 \mathrm{~cm}$, head circumference of $34 \mathrm{~cm}$ and Apgar scores of 8/10. She was transferred to the mother-baby unit soon after birth and was discharged two days later. There was no consanguinity between the twins' parents, who were young and healthy at the time of their conception. The affected child's dysmorphic features included left hemifacial microsomia, severe micrognathia, abnormal ears, bilateral preauricular tags and epibulbar dermoid in the right eye. She developed obstructive apnea due to micrognathia and required tracheostomy. Abdominal and cranial ultrasound findings were normal, as was an ophthalmological assessment. Spine $x$-ray showed hemivertebra at T9 and T10. An echocardiogram showed Tetralogy of Fallot. GTG-banded karyotyping was performed on peripheral blood cells and revealed 46,XX. Zygosity testing established the pair of twins to be monozygotic with a probability greater than 99:1.

Comment: Goldenhar syndrome was diagnosed in one of the twins described here. There are several reports of twins discordant for this disorder and therefore non-genetic factors may also play an important role, for instance vascular disruption during morphogenesis.
\end{abstract}

J Pediatr (Rio J). 2006;82(1):75-8: Goldenhar syndrome, twinning, diagnosis.

\section{Introduction}

Mandibulofacial dysostoses are conditions that affect the development of the auricular, oral and mandibular regions. ${ }^{1}$ Goldenhar syndrome is part of the oculo-auriculovertebral spectrum and is recognized as a syndrome

1. Doutorando, Faculdade de Medicina, Centro Universitário Barão de Mauá, Ribeirão Preto, SP, Brasil.

2. Médica intensivista pediátrica, Hospital Santa Casa de Misericórdia de Ribeirão Preto, SP, Brasil.

3. Doutora. Professora, Faculdade de Medicina, Centro Universitário Barão de Mauá, Ribeirão Preto, SP, Brasil.

Manuscript received Aug 09 2005, accepted for publication Oct 242005.

Suggested citation: Verona LL, Damian NG, Pavarina LP, Ferreira CH, Melo DG. Monozygotic twins discordant for Goldenhar syndrome. J Pediatr (Rio J). 2006;82:75-8. because, in addition to the mandibulofacial dysostosis, there are other vertebral anomalies and epibulbar dermoids. ${ }^{2}$ The expression of this pathology is highly variable, with $70 \%$ of patients suffering unilateral involvement and those that have bilateral conditions will be more severely affected on one side than the other. ${ }^{3}$

Studies with animal models have suggested that Goldenhar syndrome appears due to a vascular disruption in the embryo, at 35 to 40 day's gestation. This disruption impedes correct morphogenesis of structures derived from the first and second branchial arches, resulting in the clinical presentation observed at birth. 3,4

Affected children may present hypoplastic cheekbones and/or jaw; hypoplasia of the facial musculature; microtia; 
preauricular tags and dysplasia of the external ear; hemivertebra or hypoplasia of cervical, thoracic or lumbar vertebrae; epibulbar dermoids; microphthalmia; cleft lip and/or palate and cardiac, renal and/or central nervous system anomalies. Nevertheless, in function of the variability of clinical presentations, there are patients who are afflicted with minimal clinical manifestations, predominantly facial asymmetry and dysplasia of the external ear. ${ }^{3}$

The incidence of this pathology is estimated at one in every 5,600 newborn infants. ${ }^{3}$ The majority of Goldenhar syndrome cases are sporadic, but familial cases have been reported with autosomal dominant inheritance and varied expression and also cases in which there is consanguinity between parents, suggesting autosomal recessive inheritance. ${ }^{5-8}$ There are reports of discordant clinical status among monozygotic twins in the international literature, but none in Brazilian scientific literature. ${ }^{9-12}$

The authors report on a pair of female monozygotic twins where one of the children has Goldenhar syndrome while the other is healthy.

\section{Case description}

A white, female patient from Ribeirão Preto, São Paulo state. The third daughter of healthy, young, nonconsanguineous parents (mother 29 and father 34 at birth of the child). The child was delivered by caesarian preterm with a somatic Capurro age of 35 weeks and 2 days, weighing $2,170 \mathrm{~g}$ and measuring $42.5 \mathrm{~cm}$ in length and with a head circumference of 30 and Apgar scores of $3 / 7$. The child developed severe respiratory distress and was transferred to the neonatal intensive care unit (ICU). The other twin was born weighing 3,200 $\mathrm{g}$ and measuring $49 \mathrm{~cm}$ in length, with a head circumference of $34 \mathrm{~cm}$ and Apgar scores of $8 / 10$. She was transferred to the mother-baby unit with her mother and discharged 2 days after birth.

The twin that had Goldenhar syndrome presented left hemifacial microsomia, mandibular hypoplasia more severe on the left and with micrognathia, bilateral dysplasia of the external ears, bilateral preauricular tags and epibulbar dermoid in the right eye (Figures 1 and 2). She developed obstructive apnea due to micrognathia and required tracheostomy.

Ultrasound of the cranium and abdomen were normal and $x$-rays of the spine showed hemivertebra at T9/T10, the echocardiogram detected tetralogy of Fallot, karyotyping of lymphocytes from peripheral blood with GTG banding was normal $(46, X X)$. An ophthalmological assessment was normal. It was proven that these were monozygotic twins with $99.99 \%$ certainty by means of molecular testing with microsatellite mapping.

The child progressed with ongoing improvement to the respiratory condition. She was discharged from hospital aged 34 days, still with the tracheostomy, but breathing room air. She is currently in outpatients follow-up, awaiting heart surgery and later, aesthetic corrective measures to her facial anomalies.

\section{Discussion}

Monozygotic twins are themselves a manifestation of the most common morphogenesis defect in the human species and it is therefore no surprise that other anomalies are also more common in these cases. ${ }^{7}$ In the majority of cases, monozygotic twins share a single placenta and so vascular disruptions are common, which explains the

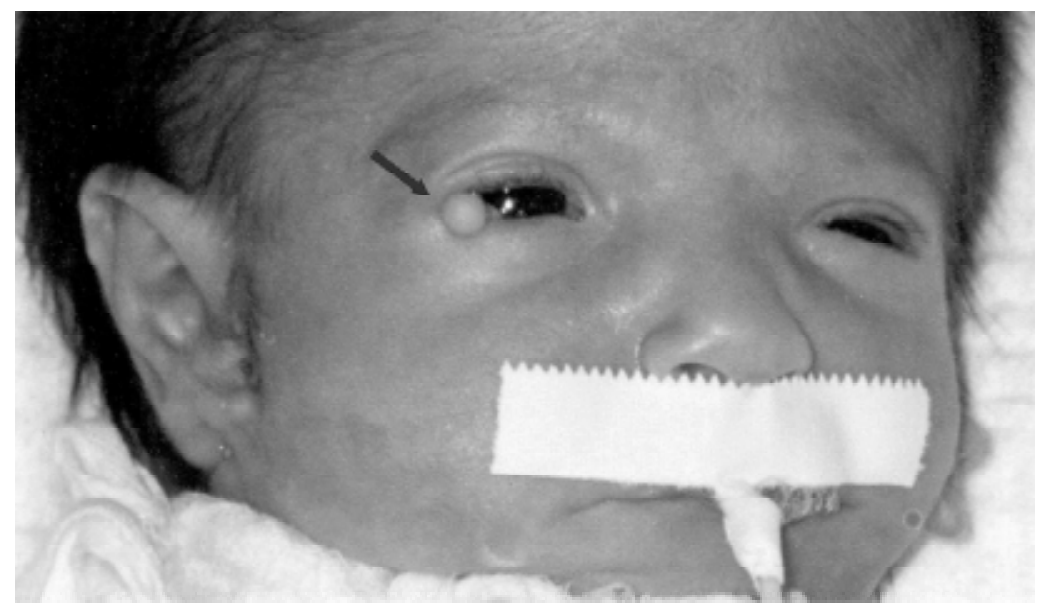

Figure 1 - Facial asymmetry, micrognathia, narrowing of the eyelid folds, which are turned downwards, and epibulbar dermoid in the right eye (arrow) 


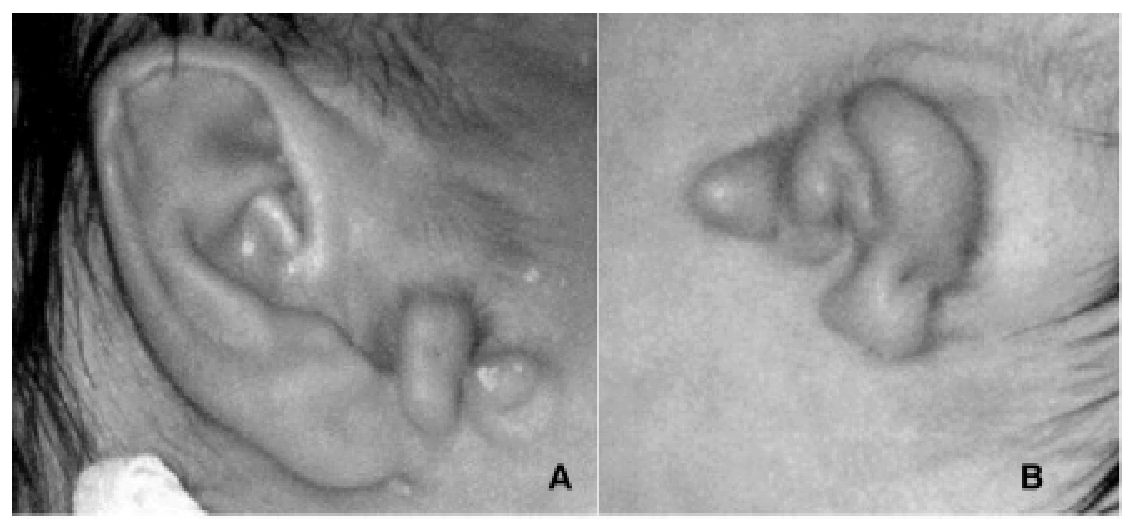

Figure 2 - Bilateral dysplasia of the external ears, bilateral preauricular tags (A). Dysplasia of the left external ear is more important (B)

divergent clinical presentation at birth of individuals who are genetically identical. 13

The etiology of Goldenhar syndrome is itself related to vascular disruption, particularly of the stapedial artery (which is a branch of the internal carotid) and the external carotid, which alters the morphogenesis of structures derived from the first and second branchial arches, and it is from this that all of the clinical manifestations stem. ${ }^{7}$

It is believed that Goldenhar syndrome is part of a more complex clinical presentation of first and second branchial arches defects, most often known as oculoauriculo-vertebral spectrum and characterized by the presence of additional vertebral anomalies and epibulbar dermoids. ${ }^{14}$

Without doubt, the most common anomalies with the oculo-auriculo-vertebral spectrum are hemifacial microsomia and dysplasia of the external ear, observed in $65 \%$ of cases. Epibulbar tumors and congenital heart disease affect around $50 \%$ of patients, with the tetralogy of Fallot the most common defect. ${ }^{3}$ thirty percent of patients exhibit spine abnormalities, varying from spina bifida, through hemivertebra, to vertebral fusion and hypoplasia. Just $5 \%$ exhibit abnormalities of the trachea and kidneys; and it is estimated that 5 to $10 \%$ have some degree of mental deficiency, with or without structural central nervous system abnormalities. ${ }^{15}$ Depending upon the pattern of anomalies emphasized by different authors, the oculo-auriculo-vertebral spectrum can receive other names such as facio-auriculo-vertebral spectrum, hemifacial microsomia or otomandibular dysostosis. 16

Since clinical manifestation is of such a heterogeneous nature, it is important to be alert to other diagnostic possibilities, such as the VACTERL and CHARGE associations; and the Townes-Brocks and Branchio-OtoRenal syndromes. Differential diagnosis for these entities is based on the pattern of abnormalities observed. ${ }^{17}$

Since the majority of Goldenhar syndrome cases are sporadic, the risk of recurrence is low, although some authors have reported empirical risk of up to $6 \%$ for first degree relatives of affected children. ${ }^{9}$ In function of the variability of expression, family-by-family evaluation should be considered in order to offer correct genetic counseling in cases where Goldenhar syndrome is diagnosed.

\section{References}

1. Singh DJ, Bartlett SP. Congenital mandibular hypoplasia: analysis and classification. J Craniofac Surg. 2005;16:291-300.

2. Hunt JA, Hobar PC. Common craniofacial anomalies: the facial dysostoses. Plast Reconstr Surg. 2002;110:1714-25.

3. Gorlin RL. Branchial arch and oro-acral disorders. In: Gorlin JJ, Cohen Jr MM, Hennekam RC, editors. Syndromes of the head and neck. London: Oxford University Press; 2001. p. 790-97.

4. Soltan HC, Holmes LB. Familial occurrence of malformations possibly attributable to vascular abnormalities. J Pediatr. 1986;108:112-4.

5. Regenbogen L, Godel V, Goya V, Goodman RM. Further evidence for an autosomal dominant form of oculoauriculovertebral dysplasia. Clin Genet. 1982;21:161-7.

6. Setzer ES, Ruiz-Castaneda N, Severn C, Ryden S, Frias JL. Etiologic heterogeneity in the oculoauriculovertebral syndrome. J Pediatr. 1981;98:88-90.

7. Burck U. Genetic aspects of hemifacial microsomia. Hum Genet 1983;64:291-6.

8. Stoll C, Viville B, Treisser A, Gasser B. A family with dominant oculoauriculovertebral spectrum. Am J Med Genet. 1988;78: 345-9.

9. Ryan CA, Finer NN, Ives E. Discordance of signs in monozygotic twins concordant for the Goldenhar anomaly. Am J Med Genet. $1988 ; 29: 755-61$ 
78

10. Terhaar B. Oculo-auriculo-vertebral dysplasia (Goldenhar's syndrome) concordant in identical twins. Acta Genet Med. Gemellol. 1972;21:116-24.

11. Boles DJ, Bodurtha J, Nance WE. Goldenhar complex in discordant monozygotic twins: a case report and review of the literature. Am J Med Genet. 1987;28:103-9.

12. Krause U. The syndrome of Goldenhar affecting two siblings. Acta Ophthal. 1970;48:494-9.

13. Schinzel AA, Smith DW, Miller JR. Monozygotic twinning and structural defects. J Pediatr. 1979;95:921-30.

14. Jones KL. Oculo-auriculo-vertebral spectrum. In: Smith's recognizable patterns of human malformations. 5th ed. Philadelphia: W. B. Saunders Co.; 1997. p. 642-5.

15. Schrander-Stumpel CT, de Die-Smulders CE, Hennekam RC, Fryns JP, Bouckaert PX, Brouwer OF, et al. Oculoauriculovertebral spectrum and cerebral anomalies. J Med Genet. 1992;29:326-31.
Monozygotic twins discordant for Goldenhar syndrome - Verona LL et al.

16. Online Mendelian Inheritance in Man, OMIM [site na Internet]. Johns Hopkins University, Baltimore, MD. MIM Number: [\%164210]. http://www.ncbi.nlm.nih.gov/omim. Access: 29/ $09 / 2005$.

17. Rollnick BR. Oculoauriculovertebral anomaly: variability and causal heterogeneity. Am J Med Genet Suppl. 1988;4:41-53.

\section{Correspondence:}

Débora Gusmão Melo

Avenida Caramuru, 630, bloco 01, apto. 401, Bairro República

CEP 14030-000 - Ribeirão Preto, SP - Brazil

Tel.: + 55 (16) 602.2598/3911.6719

Fax: +55 (16) 633.0485

E-mail: debora.gusmao@gmail.com 